\title{
Current controlled current differential current conveyor: a novel building block for analog signal processing
}

\author{
Adib Abrishamifar ${ }^{\text {a) }}$, Yasha Karimi, and Mir Mohammad Navidi \\ Electrical and Electronic Engineering faculty, Iran University of Science and \\ Technology (IUST), Tehran 16846, Iran \\ a)abrishamifar@iust.ac.ir
}

\begin{abstract}
In this paper, a novel active block for analog signal processing is presented, namely the current controlled current differential current conveyor (CCCDCC). This multi terminal block has most features of the well-known CCII (Second Generation Current Conveyor) and CCCDTA (Current Controlled Current Differencing Tranconductance Amplifier) to simplify the realization of current-mode analog filters suitable for signal processing. The proposed block and its applications were simulated in $0.18 \mu \mathrm{m}$ CMOS process at $\pm 0.9 \mathrm{~V}$ supply voltages. All of results were obtained by Hspice and with a high detailed transistor library.
\end{abstract}

Keywords: current conveyor, filter realization, analog processing circuit, current differential, current-mode

Classification: Integrated circuits

\section{References}

[1] A. Mahmoodi and A. Abrishamifar, "A novel current conveyor with high functionality and optimized ports," IEICE Electron. Express, vol. 7, no. 19 , pp. 1480-1485, 2010.

[2] C. C. Ming, A. M. Soliman, and M. N. S. Swamy, "Analytical synthesis of low-sensitivity high-order voltage-mode DDCC and FDCCII-grounded $\mathrm{R}$ and C all-pass filter structures," IEEE Trans. Circuits Syst. I, Reg. Papers, vol. 54, no. 7, pp. 1430-1443, 2007.

[3] Q. Zhang, C. Wang, J. Sun, and S. Du, "A new type of current conveyors and its application in fully balanced differential current-mode elliptic filter design," J. Electrical Engineering, vol. 62, no. 3, pp. 126-133, 2011.

[4] H. O. Elwan and A. M. Soliman, "Novel CMOS differential voltage current conveyor and its applications," IEE Proceedings G: circuits Devices Systems, vol. 144, pp. 195-197, 1997.

[5] A. A. El-Adawy, A. M. Soliman, and H. O. Elwan, "A novel fully differential current conveyor and applications for analog VLSI," IEEE Trans. Circuits Syst. II, Analog Digit. Signal Process., vol. 47, pp. 306-309, 2000. 
[6] A. Alzaher, H. Elwan, and M. Ismail, "CMOS fully balanced second generation current conveyor," IEEE Trans. Circuits Syst. II, Analog Digit. Signal Process., vol. 50, pp. 278-284, 2003.

[7] D. Biolek, "CDTA-Building block for current-mode analog signal processing," Proc. ECCTD 03, Cracow, Poland, vol. 3, pp. 397-400, 2003.

[8] A. Lahiri, "New current-mode quadrature oscillators using CDTA," IEICE Electron. Express, vol. 6, no. 3, pp. 135-140, 2009.

[9] M. Siripruchyanun and W. Jaikla, "CMOS current-controlled current differencing transconductance amplifier and applications to analog signal processing," AEU - International Journal of Electronics and Communications, vol. 62, no. 4, pp. 277-287, 2008.

[10] J. J. F. Rijns, "54 MHz switched capacitor video channel equalizer," Electronics Letters, vol. 29, no. 25, pp. 2181-2182, Dec. 1993.

\section{Introduction}

The interest in designing current-mode circuits mainly originate from their higher bandwidth, speed advantages, simpler circuit, and wider dynamic range $[1,2,3,4,5]$. Current conveyors (CC) as an example of currentmode circuits are helpful devices widely used in analog signal processing. Several applications such as filtering, inductor simulation, impedance converting, amplification, and oscillation are acquirable with current conveyors. Many types of CCs have been reported since 1968, but they principally function by directing a current and voltage signal from one port to another.

Second generation current conveyors (CCII) are comprehensive building blocks for a variety of circuits. Hence, many CCII's modifications have been introduced to increase the usefulness of this element. Differential difference current conveyor (DDCC) [4], differential voltage current conveyors (DVCC) [5], and fully differential second generation current conveyor (FDCCIIs) [6] are a few examples of these elements. In addition to modified circuit, some analog block also drive out from current conveyors, as an example, CDTA (Current Differencing Transconductance Amplifier), introduced by Biolek [7], has been found as a useful analog block for current-mode signal processing [8]. Recently, CCCDTA (Current Controlled Current Differencing Transconductance Amplifier) modified CDTA whose current inputs resistances are controllable, is proposed by Siripruchyanun [9].

One of the most uses of CCCDTA and other mentioned current-mode blocks is realizing filters. Hence many structures for filters have been presented by means of various blocks; still, need at least two building blocks for realizing a current-mode high-pass filter seems necessary in most available current conveyor based building blocks.

This paper introduces a new element, so called a current controlled current differential current conveyor (CCCDCC). This block has differencing feature of CDTA and CCII benefits, but main advantage of proposed block is that a high-pass $\backslash$ low-pass filter can be easily realized with just one CCCDCC. 


\section{The proposed novel analog block}

The CCII is a single-ended device, while most modern high performance ana$\log$ integrated circuits use differential signal paths. In order to use benefits of differential feature and customary applications of CCII, we presented a novel block, CCCDCC, whose circuit symbol and internal circuitry are shown in Fig. 1 (a) and Fig. 1 (c), respectively. Here, $\mathrm{X}_{1}$ and $\mathrm{X}_{2}$ behave as differential current input tracking $\mathrm{Y}$ voltage owing to their input resistance. $\mathrm{Z}_{\mathrm{d}}$ and $\mathrm{Z}_{-\mathrm{d}}$ are the differential current output terminals, $\mathrm{Z}$ and $\mathrm{Z}_{-}$are the replica of terminal $\mathrm{X}_{1}$ input current providing negative or positive CCII. The number of current output terminals can be increased if necessary. $\mathrm{I}_{\mathrm{B}}$ implies to bias current of CCCDCC. Regarding all the current directions flow to inside of the block, Eq. (1) represents the terminal relations of the device. The resistances of current inputs can be obtained by direct analysis, if $\mathrm{g}_{\mathrm{m} 1}=\mathrm{g}_{\mathrm{m} 5}$ and $\mathrm{g}_{\mathrm{m} 2}=\mathrm{g}_{\mathrm{m} 6}=\mathrm{g}_{\mathrm{m}}$ input resistance terminal will be as Eq. (2) where $\beta_{n}=\mu_{n} C_{o x}(W / L)$ is the physical parameter of MOS transistor. Hence $\mathrm{R}_{\mathrm{X} 1}$ and $\mathrm{R}_{\mathrm{X} 2}$ can be controlled by bias current. We employ class AB CCII which has low power consumption and high frequency. Also, using low voltage low power current mirrors (CM) [10] cause high output resistance while transistors work properly in $0.18 \mu \mathrm{m}$ CMOS technology; the gate terminal of upper MOSFETs of CMs, like $\mathrm{M}_{\mathrm{n} 1}$ and $\mathrm{M}_{\mathrm{P} 1}$, are connected to ground, and are not shown for simplicity.

$$
\begin{gathered}
{\left[\begin{array}{c}
\mathrm{V}_{\mathrm{X} 1} \\
\mathrm{~V}_{\mathrm{X} 2} \\
\mathrm{I}_{\mathrm{Y}} \\
\mathrm{I}_{\mathrm{Z}} \\
\mathrm{I}_{-\mathrm{Z}} \\
\mathrm{I}_{\mathrm{Zd}} \\
\mathrm{I}_{-\mathrm{Zd}}
\end{array}\right]=\left[\begin{array}{ccccccc}
\mathrm{R}_{\mathrm{X} 1} & 0 & 1 & 0 & 0 & 0 & 0 \\
\mathrm{R}_{\mathrm{X} 2} & 0 & 1 & 0 & 0 & 0 & 0 \\
0 & 0 & 0 & 0 & 0 & 0 & 0 \\
1 & 0 & 0 & 0 & 0 & 0 & 0 \\
-1 & 0 & 0 & 0 & 0 & 0 & 0 \\
-1 & 1 & 0 & 0 & 0 & 0 & 0 \\
1 & -1 & 0 & 0 & 0 & 0 & 0
\end{array}\right]\left[\begin{array}{c}
\mathrm{I}_{\mathrm{X} 1} \\
\mathrm{I}_{\mathrm{X} 2} \\
\mathrm{~V}_{\mathrm{Y}} \\
\mathrm{V}_{\mathrm{Z}} \\
\mathrm{V}_{-\mathrm{Z}} \\
\mathrm{V}_{\mathrm{Zd}} \\
\mathrm{V}_{-\mathrm{Zd}}
\end{array}\right]} \\
\mathrm{R}_{\mathrm{X} 1, \mathrm{X} 2}=\frac{1}{\mathrm{~g}_{\mathrm{m} 2}+\mathrm{g}_{\mathrm{m} 6}}-\frac{\mathrm{I}_{\mathrm{B}}}{\mathrm{I}_{\mathrm{in}}\left(\mathrm{g}_{\mathrm{m} 2}+\mathrm{g}_{\mathrm{m} 6}\right)}\left(\frac{\mathrm{g}_{\mathrm{m} 2}}{\mathrm{~g}_{\mathrm{m} 1}}-\frac{\mathrm{g}_{\mathrm{m} 6}}{\mathrm{~g}_{\mathrm{m} 5}}\right)=\frac{1}{2 \mathrm{~g}_{\mathrm{m}}}=\frac{1}{\sqrt{8 \beta_{\mathrm{n}} \mathrm{I}_{\mathrm{B} 1}}}
\end{gathered}
$$

\section{Applications}

Generally, a current-mode high pass filter can be brought about by a low pass filter and a differencing block as shown in Fig. 1(b). Disadvantage of this realization is using two analog blocks for a first order high-pass filter. Therefore, if we are going to realize a high-pass filter by means of analog processors or Field Programmable Analog Array (FPAA), internal connection of two blocks will make parasitic effects. In order to decrease these effects we use presented blocks to form a high-pass and low-pass filter by just one CCCDCC. Fig. 1 (d) depicts the filters whose functions can be expressed by:

$$
\mathrm{I}_{\mathrm{HP}}=-\left(\frac{\mathrm{I}_{\mathrm{in}}}{\mathrm{R}_{\mathrm{X} 2} \mathrm{C}_{1} \mathrm{~S}+1}-\mathrm{I}_{\mathrm{in}}\right)=\left(\frac{\mathrm{R}_{\mathrm{X} 2} \mathrm{C}_{1} \mathrm{SI}_{\mathrm{in}}}{\mathrm{R}_{\mathrm{X} 2} \mathrm{C}_{1} \mathrm{~S}+1}\right)
$$




$$
\mathrm{I}_{\mathrm{LP}}=\left(-\mathrm{I}_{\mathrm{HP}}+\mathrm{I}_{\mathrm{in}}\right)=\left(\frac{\mathrm{I}_{\mathrm{in}}}{\mathrm{R}_{\mathrm{X} 2} \mathrm{C}_{1} \mathrm{~S}+1}\right)
$$

The cutoff frequency and its sensitivities are obtained as Eq. (5)

$$
\omega_{\mathrm{c}}=\frac{1}{\mathrm{R}_{\mathrm{X} 2} \mathrm{C}_{1}}, \quad \mathrm{~S}_{\mathrm{R}_{\mathrm{X} 2} \mathrm{C}_{1}}^{\omega_{\mathrm{c}}}=-1
$$

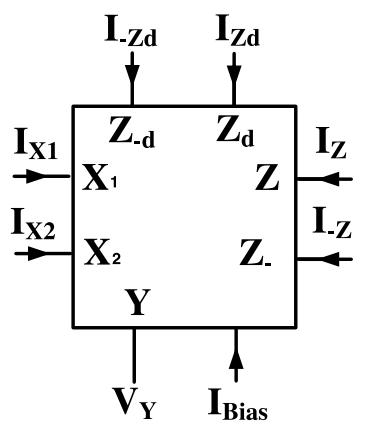

(a)

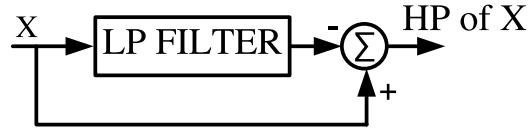

(b)

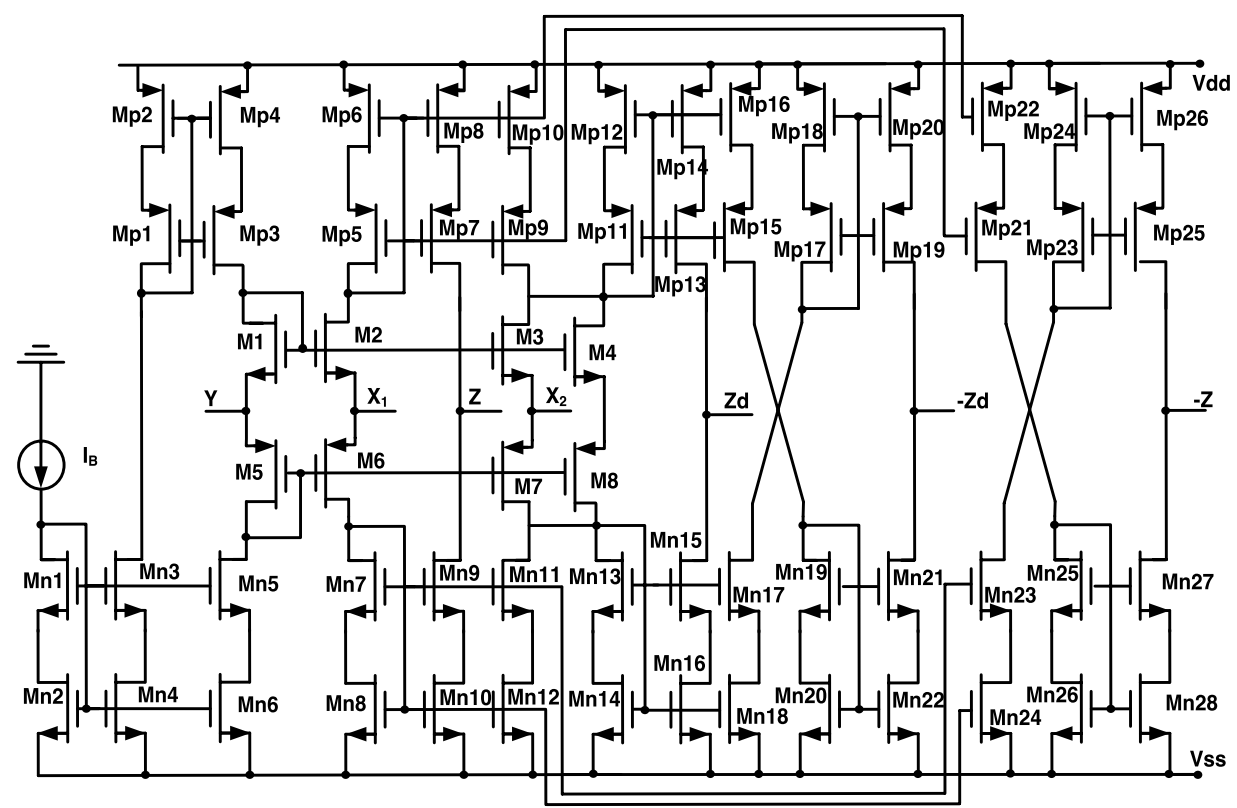

(c)

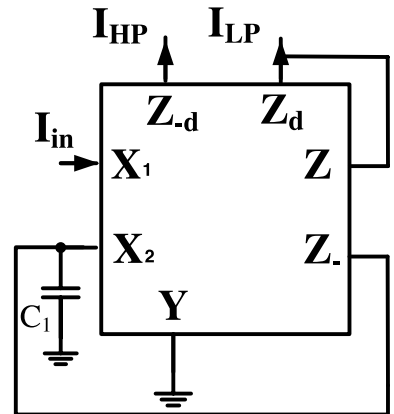

(d)

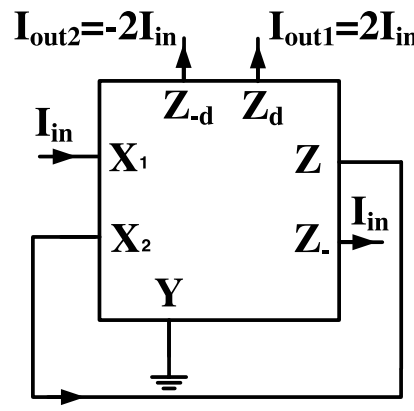

(e)

Fig. 1. The proposed CCCDCC and its applications (a) Symbol (b) Conventional method for realizing High pass filter (c) CMOS internal circuit (d) LP and HP filter (e) A Current Doubler 


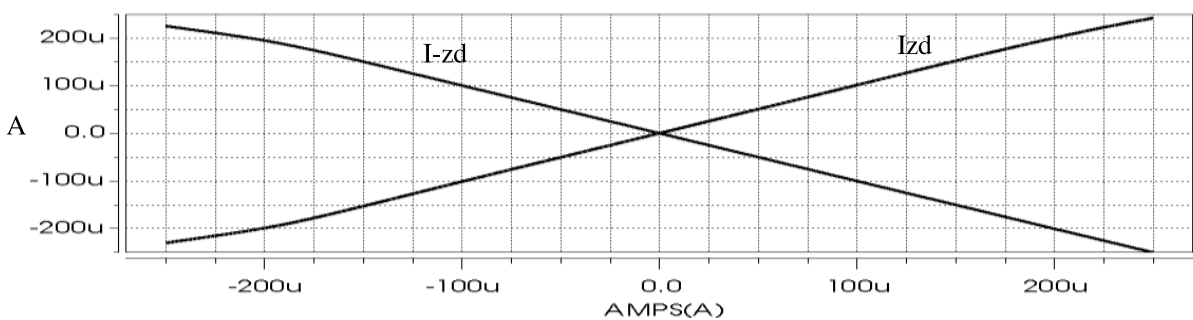

(a)

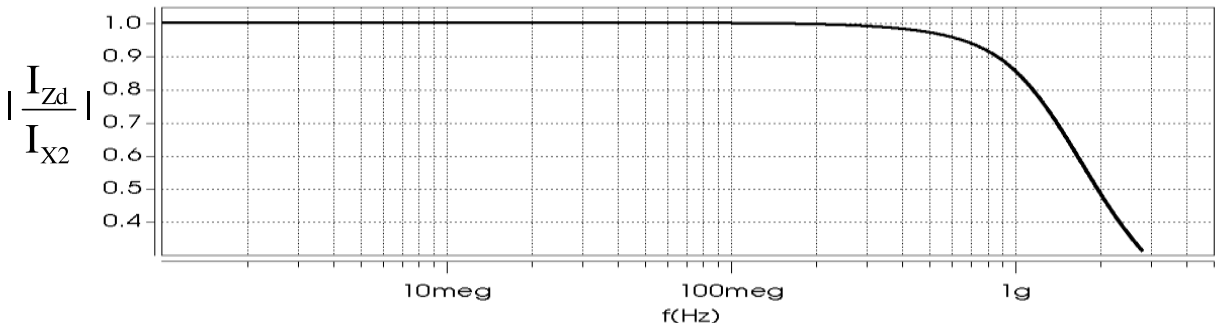

(b)

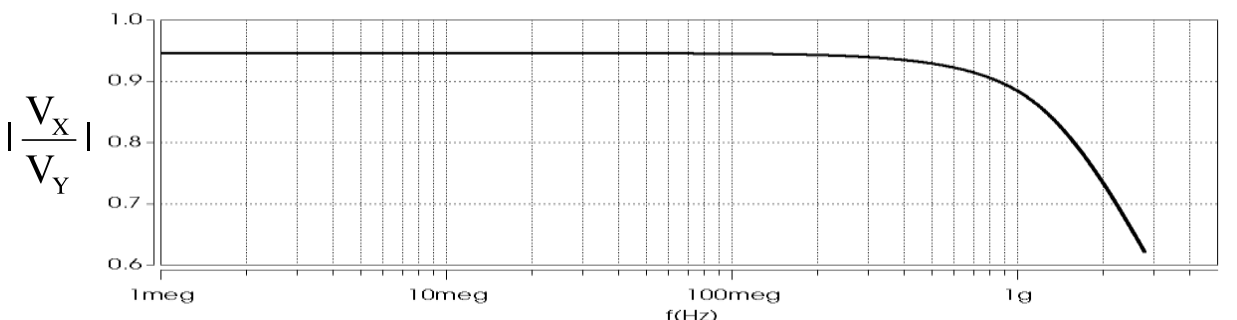

(c)

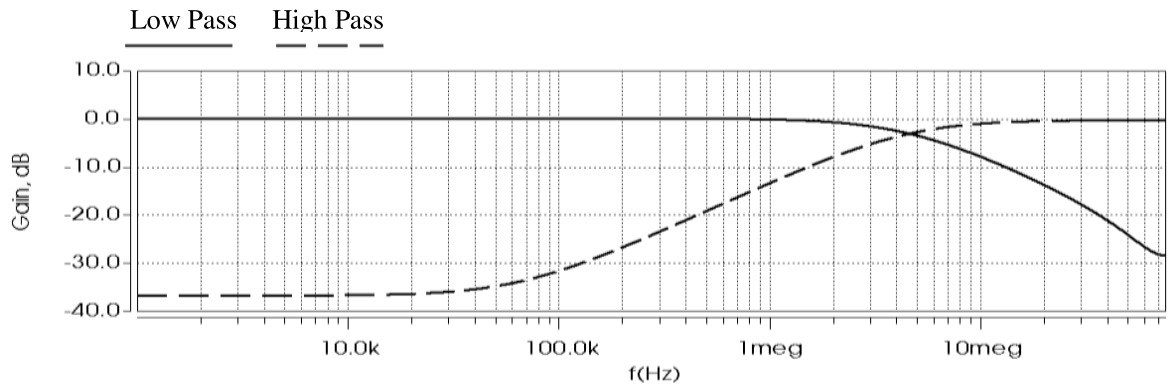

(d)

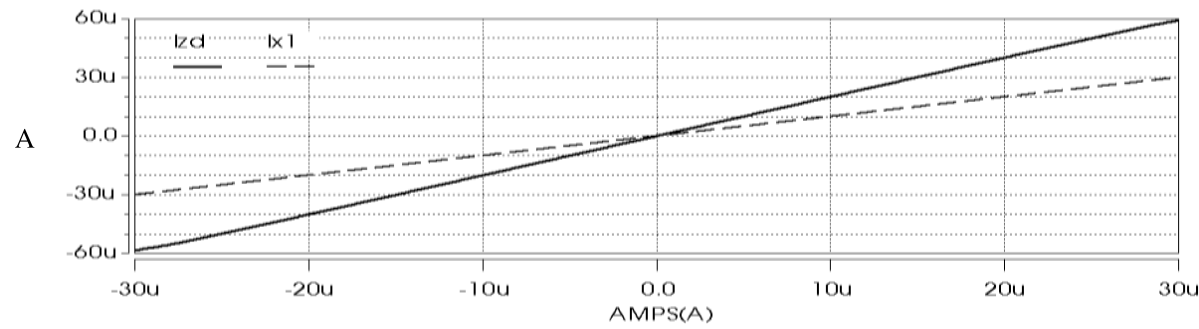

(e)

Fig. 2. Simulation results of proposed CCCDCC and its applications (a) the dc current transfer (b) The current gain (c) The Voltage gain (d) The Gain of high/low pass filter (e) The dc response of current doubler 
Another simple application is doubling of input current which can be achieved by means of just one CCCDCC shown in Fig. 1 (e).

\section{Simulation results and comparison}

The proposed novel building block was designed and simulated in $0.18 \mu \mathrm{m}$ CMOS technology and the results were obtained by Hspice simulator.

The dimension values of transistors M1-M4, M5-M8, Mn1-Mn6, Mn7Mn28, Mp1-Mp4, Mp5-Mp26, are $10 \mu \mathrm{m} / 0.18 \mu \mathrm{m}, \quad 4.14 \mu \mathrm{m} / 0.18 \mu \mathrm{m}$, $4.05 \mu \mathrm{m} / 0.18 \mu \mathrm{m}, 4.14 \mu \mathrm{m} / 0.18 \mu \mathrm{m}, 8 \mu \mathrm{m} / 0.18 \mu \mathrm{m}$, and $10 \mu \mathrm{m} / 0.18 \mu \mathrm{m}$, respectively.

Some simulation results are demonstrated in Fig. 2; the ac current gain and dc transfer response between $\mathrm{X}_{2}$ port to $\mathrm{Z}_{\mathrm{d}}$ and $\mathrm{Z}_{-\mathrm{d}}$ ports are shown in Fig. 2 (b) and Fig. 2 (a), respectively. The ac voltage gain is also shown in Fig. 2 (c). Fig. 2 (d) represents the magnitude responses of the first-order high pass and low pass filter, respectively, designed at $f_{C}=4.42 \mathrm{MHz}: C=30 \mathrm{pF}$ and $\mathrm{R}_{\mathrm{X} 2}=1.2 \mathrm{~K} \Omega$. Finally, Fig. 2 (e) depicts the current output of proposed current doubler.

The power supply was $\pm 0.9 \mathrm{~V}$ while the bias current was $\mathrm{I}_{\mathrm{b}}=30 \mu \mathrm{A}$.

Because of the fact that proposed CCCDCC is a novel block, comparison of the presented work with other blocks is not quite fair, as some blocks maybe design for specific purpose. But to show that the characteristics of the presented circuits are not far from other recent well-known blocks, we compare our results with similar works in Table I. The output resistance, current linear range, its power consumption, and THD are better, compare to what are reported in $[1,9]$.

Table I. Comparison of presented CCCDCC with similar works

\begin{tabular}{lccc}
\hline Parameters & Presented CCCDCC & {$[1]$} & {$[9]$} \\
\hline Technology $(\mu \mathrm{m})$ & 0.18 & 0.18 & 0.35 \\
\hline Voltage Suply(V) & \pm 0.9 & 1.8 & \pm 1.5 \\
\hline $\begin{array}{l}\text { Power } \\
\text { consumption(mW) }\end{array}$ & 0.706 & 1.71 & 1.48 \\
\hline $\begin{array}{l}\text {-3dB bandwidth } \\
\quad(\mathrm{GHz})\end{array}$ & $1.377(\mathrm{Izd} / \mathrm{Ix} 2)$ & $0.574(\mathrm{Iz} / \mathrm{Ix} 1)$ & $0.311(\mathrm{Izd} / \mathrm{Ix} 2)$ \\
& $\begin{array}{l}1.071(\mathrm{Izd} / \mathrm{Ix} 1) \\
\text { 1.203 }(\mathrm{Iz} / \mathrm{Ix} 1)\end{array}$ & $2.5(\mathrm{Vy} / \mathrm{Vx})$ & $0.282(\mathrm{Izd} / \mathrm{Ix} 1)$ \\
& $2.5(\mathrm{Vy} / \mathrm{Vx})$ & & \\
\hline $\begin{array}{l}\text { Input current } \\
\text { linear range }\end{array}$ & $-200 \mu \mathrm{A}$ to $200 \mu \mathrm{A}$ & $-200 \mu \mathrm{A}$ to $200 \mu \mathrm{A}$ & $-100 \mu \mathrm{A}$ to $100 \mu \mathrm{A}$ \\
\hline $\begin{array}{l}\text { Voltage dynamic } \\
\text { range }\end{array}$ & $-0.45 \mathrm{~V}$ to $0.45 \mathrm{~V}$ & $-0.4 \mathrm{~V}$ to $0.4 \mathrm{~V}$ & $\mathrm{~N} / \mathrm{R}$ \\
\hline THD $(\%)$ & & & $\mathrm{N} / \mathrm{R}$ \\
\hline $\begin{array}{l}\mathrm{Rx} 1 \text { and } \mathrm{Rx} 2 \\
\text { range }\end{array}$ & 0.555 & 1.02 & $0.821 \mathrm{k} \Omega$ to \\
\hline $\mathrm{Rz}, \mathrm{Rzd}$ & $31.8 \mathrm{k} \Omega$ & $\mathrm{N} / \mathrm{R}$ & $25.1 \mathrm{k} \Omega$ \\
\hline
\end{tabular}




\section{Conclusion}

A novel current-conveyor-based building block was discussed. Due to its differential and CCII features, a low-pass/high-pass filter can be realized by just one proposed block, CCCDCC. Moreover, the device had high performance and could operate at high frequencies. Thus, it can be applied in high frequency circuits such as video or RF processors. The design was simulated in $0.18 \mu \mathrm{m}$ CMOS technology. The results were obtained by Hspice simulator and a couple of applications were proposed. 